\title{
Educação Popular: Gênero, Expressão Fotográfica e Reforma Agrária no Rio de Janeiro
}

\author{
Juliana Soares Dionísio, Leandro de Souza Silva² e Paulo Pires de \\ Queiroz $^{3}$
}

${ }^{1}$ Programa de Pós-graduação em Ciências, Tecnologia e Inclusão - Instituto de Biologia Universidade Federal Fluminense, Brasil | julianasdq@id.uff.br; jujulianadionisio@gmail.com https://orcid.org/0000-0002-6954-8301

${ }^{2}$ Programa de Pós-graduação em Ciências, Tecnologia e Inclusão - Instituto de Biologia Universidade Federal Fluminense, Brasil | Departamento de Artes Visuais, Colégio Pedro II, Brasil | souzaleandro@id.uff.br | http://orcid.org/0000-0002-6140-9681

${ }^{3}$ Faculdade de Educação - Universidade Federal Fluminense, Brasil | ppqueiroz@yahoo.com.br | https://orcid.org/0000-0002-0609-6424

\begin{abstract}
Resumo: Introdução. A educação popular, em sua práxis inclusiva e contra-hegemônica, propõe constante reflexão a respeito dos aspectos políticos, sociais e culturais de suas e seus protagonistas. A essa abordagem somam-se diversos temas que, em suas visualidades, nos ensinam sobre os modos de ver camponês. A partir de inquietações sobre os modos como camponeses/as expressam visualmente a feminilidade e a masculinidade, intuímos investigar: De que modo a expressão fotográfica pode contribuir para o debate de gênero, no contexto da educação popular em um assentamento de reforma agrária no Rio de Janeiro? Objetivo. Avaliar a contribuição da linguagem fotográfica na promoção de uma educação popular em gênero no âmbito do assentamento. Método. A proposta fol desenvolvida através do método de pesquisa participativo. Resultados. A análise dos dados indicou a incidência das questões de gênero na vida dos/as participantes, além de apontar a utilização da fotografia como modo de expressão no cotidiano dos/as participantes. Conclusões. A pesquisa apontou que a expressão fotográfica pode auxiliar à promoção de discussões acerca das questões de gênero. Para além, pode auxiliar na expressão de visualidades e reflexão em espaços promotores da educação popular e inclusiva, pautados no acolhimento da diversidade em suas multiformes facetas.
\end{abstract}

Palavras-chave: Educação Popular; Gênero; Fotografia; Assentamento; Reforma Agrária.

Popular Education: Gender, Photographic Expression and Agrarian Reform in Rio de Janeiro

Abstract: Introduction. Popular education, in its inclusive and anti-hegemonic praxis proposes constant reflection on the political, social and cultural aspects of its and its protagonists. In addition to this approach, there are several themes that, in their visualities, teach us about the ways of seeing peasants. Based on concerns about the ways in which peasants visually express femininity and masculinity, we intend to investigate: How photographic expression can contribute to the gender debate, in the context of popular education in an agrarian reform settlement in Rio de Janeiro? Objective. Evaluate the contribution of photographic language to the promotion of popular education in gender within the settlement. Method. The proposal was developed using the participatory research method. Results. The analysis of the data indicated the incidence of gender issues in the lives of the participants, in addition to pointing out the use of photography as a way of expression in the daily lives of the participants. Conclusions. Photographic expression can help promote discussions about gender issues. In addition, it can assist in the expression of visualities and reflection in spaces that promote popular and inclusive education, based on welcoming diversity in its many facets.

Keywords: Popular Education; Genre; Photography; Settlement; Land Reform.

${ }^{1}$ Bacharel em Sociologia pela Universidade Federal Fluminense (2015). Licenciada em Ciências Sociais pela Universidade Federal Fluminense (2018). Mestre em Ciências pela Fundação Oswaldo Cruz (2020). Doutoranda em Ciências, Tecnologia e Inclusão- PGCTIn- Universidade Federal Fluminense.

${ }^{2}$ Graduado em Artes Visuais (Licenciatura Plena) pela Universidade do Grande Rio - UNIGRANRIO (2008). Especializado em Ensino da Arte pela Universidade Veiga de Almeida - UVA (2011). Mestre em Artes pela Universidade Estadual do Rio de Janeiro - UERJ (2015). Doutorando em Ciências, Tecnologia e InclusãoPGCTIn- Universidade Federal Fluminense.

${ }^{3}$ Doutor em Filosofia e Humanidades - Columbia Pacific University (1997). Professor e Pesquisador Adjunto da Faculdade de Educação na Universidade Federal Fluminense. Professor e Pesquisador no Programa de Mestrado e Doutorado EBS - Ensino em Biociências e Saúde da FIOCRUZ. Tem experiência significativa na área de Ensino e atualmente trabalha com pesquisa nas áreas de Educação, Ciências Sociais e Saúde nos âmbitos da Graduação e da Pós-Graduação. 


\section{Introdução}

A proposta deste artigo parte da vivência de um dos pesquisadores em um assentamento de reforma agrária na região norte do estado do Rio de Janeiro. Esse trabalho está situado na intersecção de temas de relevância no cotidiano camponês: Expressão Fotográfica, Gênero e Educação Popular. Nesses termos configuramos a pesquisa.

Em constante movimento, as ações culturais oriundas do campo nos ensinam sobre experiências, histórias, memórias e modos de ver que transbordam a concepção e a narrativa hegemônica a respeito de pessoas que vivem fora do contexto das grandes cidades. Esse fato se estabelece na contramão do olhar construído no imaginário social na primeira metade do século XX, cuja visão urbanocêntrica enquadra a vida das pessoas que residem fora das megalópoles como atrasada e inferior, ou ainda, como o "homem da enxada" e da "mulher da cozinha/cuidadora dos filhos", olhar que reforça estereótipos excludentes e limitados.

Através da vivência no campo de pesquisa, conhecemos o coletivo de mulheres do assentamento. Esse grupo se reunia periodicamente para pensar propostas de preparo, divulgação e venda de produtos artesanais, estéticos e medicinais oriundos da terra e produzidos no próprio local. Além disso, discutiam limites, questões e dificuldades relativas à vida cotidiana das mulheres. Diante da vivência em artes e das questões de gênero manifestas, é que apresentamos a questão de partida desse trabalho: De que modo a expressão fotográfica pode contribuir para o debate de gênero, no contexto da educação popular, em um assentamento de reforma agrária no norte fluminense? $E$ ́ importante ressaltar que a fotografia, não apenas enquanto técnica, mas como linguagem, pode atuar como veículo expressivo do imaginário social, tal qual suas questões visuais subjetivas. E, em suas aproximações e diálogos com a Educação Popular, se torna um campo apropriado, de crítica e reflexão das desigualdades de gênero.

Desse modo, o artigo propõe avaliar a contribuição da linguagem fotográfica na promoção de uma educação popular em gênero no âmbito do assentamento de reforma agrária situado na região norte fluminense. Em específico, objetiva: (1) Identificar percepções de atores e 'atrizes' do assentamento sobre questões de gênero, expressão fotográfica e educação popular; (2) Empreender Oficina Pedagógica de Criação Visual acerca de gênero, fotografia e educação popular; (3) Analisar os achados obtidos; (4) Criar exposição virtual fixa em mídia social, a partir das imagens fotográficas produzidas pelas participantes das oficinas pedagógicas. Portanto, elencamos alguns estudos fundamentais para o desenvolvimento de nosso percurso teórico-metodológico para a estruturação do texto.

\subsection{Gênero, Expressão Fotográfica e Educação Popular}

A expressão fotográfica documenta visualmente proximidades e distâncias sociais e culturais, presentes ou ausentes na imagem. Em diferentes épocas, a imagem produzida diz quem a mulher e o homem são. O que emerge da superfície da imagem fotográfica, seus recortes da vida cotidiana, da sociedade e seus saberes, contém os estranhamentos e aproximações que inauguram novos olhares sobre as pessoas e lugares no/do mundo. À luz do amplo conceito de visualidade, como um campo de batalha que converge ideias, informações e imagens (Mirzoeff, 2016), a Fotografia compõe esse conjunto de formas de ver o mundo, possibilitando sua compreensão através das criações.

O conceito desse campo de conhecimento e conjunto de práticas pedagógicas compreende as visualidades e suas relações com as realidades, permite situar questões, instituir problemáticas e vislumbrar possibilidades de compreensão de processos visuais (Dias, 2011). Nessa direção, José de Souza Martins (2016) afirma que "isto nos permitiria desenvolver interpretações sociológicas estruturais por meio da fotografia, ao expor, através da imagem, o que é próprio e explicativo de cada sociedade" (Martins, 2016, p. 25). 
Nesse sentido, compreendemos que as representações de gênero possam ser retratadas através da fotografia, externando estereótipos sociológicos e fomentando discussões e reflexões acerca da temática. Por compreendermos que os seres humanos desenvolveram inúmeras formas de expressar seus sentimentos, crenças e visões de mundo, entendemos que a fotografia é um importante mecanismo de expressão.

No que tange às desigualdades sociais de gênero, homens e mulheres encontram direitos e deveres díspares na sociedade, que são atrelados e justificados em uma diferença sexual biológica, que é ao mesmo tempo complementar. Cada sexo desempenha um papel que lhe é "estabelecido biologicamente" e dessa relação, toda a engrenagem social depende. Apenas a partir da década de 1960, com avanço de estudos feministas, surge o conceito de gênero, que atribui as desigualdades entre os sexos à uma construção social. Cabe ressaltar, que ao considerar a esfera social, o conceito não nega as características biológicas dos sexos, mas considera "a construção social e histórica produzida sobre as características biológicas" (Louro, 1997, p. 22).

Elaborar mecanismos de reprodução das desigualdades sociais é quase ou mais importante do que adquirir lucro (Althusser, 1985). Através de aparelhos ideológicos, uma sociedade, um estado, é capaz de criar bases para sua subsistência. Instituições como escola, igreja, família, espaços sociais exercem um papel primordial nesse contexto: perpetuar a ideologia da classe dominante. Esses mecanismos de reprodução das desigualdades sociais perpetuam, através de uma força invisível, suave e quase imperceptível, uma "extraordinariamente ordinária relação social" (Bourdieu, 2017, p. 12). Contudo, e a despeito dessa lógica, a educação preserva sua capacidade emancipatória ao desenvolver atores críticos do tecido social (Queiroz, 2018). Nesse sentido, se faz tão necessária a criação de mecanismos educacionais que fomentem discussões e reflexões das desigualdades de gênero. Contribuindo assim, com a desconstrução arquetípica da feminilidade e da masculinidade, acorrendo com uma sociedade mais justa e equânime.

No intuito de possibilitar que as participantes da pesquisa manifestem, através da fotografia, suas reflexões e compreensões acerca da construção social de gênero e das implicações dela em suas vidas privadas, nesse estudo avançaremos na direção da construção de espaços de educação popular que procurem promover discussões profícuas acerca da temática. Não é nosso intuito determinar que nessa proposta estejam soluções engessadas ou definitivas para a questão. Reconhecemos as incontáveis adversidades e especificidades que cada contexto social de educação formal e não formal enfrenta. Contudo, evocamos a capacidade dialógica e libertária da educação popular (Brandão \& Fagundes, 2016) e suas potencialidades enquanto mecanismo de reflexão sobre as estruturas e os processos sociais. Deste modo, elaboramos a proposta desse trabalho, intuindo a promoção de discussões sobre visualidades, inclusão e emancipação, estimulando a construção de relações de gênero mais equânimes e plurais, que consequentemente, contribuirão com a promoção de uma sociedade mais justa.

\section{Objetivos}

\subsection{Objetivo Geral}

Avaliar a contribuição da linguagem fotográfica na promoção de uma educação popular em gênero no âmbito de um assentamento de reforma agrária situado na região norte do estado do Rio de Janeiro.

\subsection{Objetivos Específicos}

1. Identificar percepções de atores/atrizes do assentamento sobre questões de gênero, expressão fotográfica e educação popular;

2. Empreender Oficina Pedagógica de Criação Visual acerca de gênero, expressão fotográfica e Educação Popular; 
3. Analisar os achados obtidos;

4. Criar exposição virtual fixa em mídia social, a partir das imagens fotográficas produzidas pelas participantes nas oficinas pedagógicas.

\section{Metodologia}

\subsubsection{Natureza da Pesquisa}

Optamos por uma abordagem qualitativa em nossa investigação, por enxergarmos a necessidade de um aprofundamento na realidade vivenciada pelos atores do campo. Por considerar o mundo dos significados das ações e relações humanas, que não podem ser percebidos ou captados por equações, médias e estatísticas (Minayo, 1993), é que dispomos dessa alternativa.

\subsubsection{Campo da Pesquisa}

A pesquisa foi empreendida através de uma metodologia participativa de coleta e análise dos dados, de convergências teórico-práticas, em um coletivo de mulheres integrado a um assentamento do Movimento dos Trabalhadores Rurais Sem Terra - MST, na região norte do estado do Rio de Janeiro. Nesse método, o saber é produzido com a participação direta dos atores do campo, por compreender que projetos de pesquisa e de extensão são construções sociais de conhecimento (Thiollent, 1984, 2018).

\subsubsection{Projeto de Assentamento de Reforma Agrária no Estado do Rio de Janeiro}

O projeto de assentamento de reforma agrária no estado do Rio de Janeiro se estabelece à margem do Rio Paraíba do Sul e no contexto político da reforma agrária na região Norte Fluminense. Como Alentejano (2011) explica, desde meados dos anos 1990 essa região foi o principal palco da luta pela terra e área onde ocorreu o maior número de ocupações e desapropriações de terra em virtude da crise do setor sucroalcooleiro, que acarretou a falência de dezenas de usinas de álcool e açúcar.

Devido à crise, o reduto tradicional de exploração desses recursos e da força de trabalho sofreu transformações que redesenharam as formas de organização social e modelos alternativos de viver na/da terra. Como fruto desse processo, assentamentos foram criados a partir da divisão das terras, consolidada em 1998 por meio da desapropriação e implementação do Projeto de Desenvolvimento do Assentamento (PDA), que envolveu os sujeitos assentados, pesquisadores e agentes técnicos do Instituto Nacional de Colonização e Reforma Agrária (INCRA).

Atualmente, segundo o órgão, 506 famílias vivem em lotes organizados em núcleos. Mais próximo do centro urbano do município de Campos dos Goytacazes - RJ, fica o Zumbi 1 , até seguir mais ao norte, onde se localiza o Zumbi 5, que atravessa os limites do município até São Francisco de Itabapoana, município este, próximo ao limite do estado do Espírito Santo.

\subsubsection{Atores e 'Atrizes’ da Pesquisa}

Atuaram nessa investigação nove participantes de um coletivo de mulheres de um assentamento localizado no Rio de Janeiro. A inclusão da categoria 'atrizes' é uma opção das/os autoras/es do artigo por reconhecerem que este termo insere uma proposta adequada ao debate de gênero. A seleção do grupo se deu pela vivência prévia básica com expressões artísticas no coletivo. 
Buscamos identificar as leituras das participantes acerca da vivência das questões de gênero, da expressão fotográfica e da Educação Popular. Apenas duas das participantes não residiam mais no assentamento, contudo, permaneciam em contato direto, partilhando vivências e contribuindo com o grupo. Em sua totalidade, as participantes do coletivo concordaram com a participação na pesquisa. Estendemos o convite para homens que possuíam relação direta com elas, entretanto até o momento, não tivemos retorno deles.

Tabela 1. Caracterização das participantes.

\begin{tabular}{|c|c|c|c|c|c|c|}
\hline $\begin{array}{l}\text { Participantes } \\
\text { da pesquisa }\end{array}$ & Sexo & Idade & Cor & $\begin{array}{c}\text { Reside com } \\
\text { quantas } \\
\text { pessoas }\end{array}$ & $\begin{array}{l}\text { Responsável pela } \\
\text { renda familiar }\end{array}$ & Formação \\
\hline Okoye & Feminino & +30 & Preta & 02 & A própria & Pós-graduação \\
\hline Vixen & Feminino & +30 & Preta & 03 & $\begin{array}{l}\text { A própria e } \\
\text { cônjuge }\end{array}$ & $\begin{array}{l}\text { Fundamental } \\
\text { Incompleto }\end{array}$ \\
\hline Iron & Feminino & Entre 25 e 30 & Preta & 01 & A própria & Ensino Médio \\
\hline Riri & Feminino & +30 & Preta & Mora sozinha & A própria & Pós-graduação \\
\hline Nakia & Feminino & Entre 25 e 30 & Parda & 03 & Cônjuge & Ensino Médio \\
\hline Nubia & Feminino & +30 & Parda & 02 & Cônjuge & $\begin{array}{l}\text { Fundamental } \\
\text { Incompleto }\end{array}$ \\
\hline Storm & Feminino & +30 & Preta & +03 & $\begin{array}{l}\text { A própria e } \\
\text { cônjuge }\end{array}$ & Superior \\
\hline Monica & Feminino & +30 & Preta & +03 & A própria & Superior \\
\hline Fatality & Feminino & Entre 10 e 15 & Preta & +03 & Pai & $\begin{array}{l}\text { Fundamental } \\
\text { completo }\end{array}$ \\
\hline
\end{tabular}

Conforme o quadro acima, as participantes da pesquisa possuíam idade superior a 30 anos, majoritariamente pretas. Residindo com famílias de tamanhos diversos, em sua maioria, contribuem diretamente com a manutenção econômica do núcleo familiar. As participantes possuíam formação escolar variada. Essas informações foram coletadas através de um questionário misto virtual da plataforma Google. Este foi subdividido em três blocos de perguntas assentados sobre os conceitos da investigação: Educação Rural; Gênero e Expressão Fotográfica. Cada bloco contou com cinco perguntas, que alternavam entre questões fechadas e abertas. Devido às impossibilidades de aproximação presencial ocasionadas pela pandemia do novo Coronavírus (COVID-19), optamos pela utilização de ferramentas remotas.

Todas concordaram em participar da investigação de forma voluntária, contribuindo com suas experiências e vivências para o desenvolvimento do trabalho. As normas e parâmetros éticos para a realização de pesquisa com seres humanos foram observadas e respeitadas durante todo o processo investigativo.

\subsubsection{Estratégia Metodológica}

A estratégia metodológica foi subdividida em três etapas considerando o alcance dos objetivos da investigação. São elas:

1. Fase Diagnóstica - Composta da aplicação de questionário com questões mistas, com o intuito de verificar o conhecimento dos atores do campo sobre os conceitos pilares da investigação, a saber: Educação Rural; Gênero e Expressão Fotográfica.

2. Fase Interventora - Com base na análise dos dados recolhidos na primeira etapa, seguiremos à realização da Oficina Pedagógica de Criação Visual, intuindo a construção do conhecimento aplicado às situações da vida cotidiana no assentamento por meio da linguagem fotográfica.

3. Fase Avaliativa - Nessa etapa será aplicado novo questionário misto para auferir os resultados da fase dois. 
Além disso, serão coletados dados documentais que regulam as relações - leis externas e regimentos internos que regulamentam as relações interpessoais, documentos fotográficos produzidos durante as oficinas e o registro em diário de campo.

Para análise dos dados, faremos uso do instrumento metodológico Triangulação de Dados (Triviños, 1987). Este, possibilita uma convergência teórico-prática que permite ao/à pesquisador/a ampliar o universo de informações que cercam o objeto estudado. Este instrumento é constituído por uma divisão de interesses em três fases: (1) Processos e produtos centrados no sujeito; (2) Elementos desenvolvidos pelo meio do sujeito e que incidem sobre o desenvolvimento comunitário; (3) Processos e produtos originados pela estrutura macro-social no qual o campo se insere. Apresentaremos a seguir, os objetivos da investigação. Os objetivos específicos foram pensados de modo a tornar possível o alcance do objetivo geral, possibilitando assim, o encontro de respostas à questão de partida do trabalho.

\section{Conclusões}

Na busca do alcance de nosso primeiro objetivo específico, a saber: Identificar percepções de atores/atrizes do assentamento sobre questões de gênero, expressão fotográfica e educação popular, estabelecemos a primeira etapa deste trabalho. Optamos pela utilização de um questionário de perguntas mistas online, o que nos permitiu identificar as percepções dos atores e atrizes do campo acerca dos conceitos pilares desse trabalho.

As respostas colhidas apontaram para a incidência das questões de gênero sobre as vidas das participantes ou de pessoas próximas, as quais apontaram para modos de vida socialmente construídos e determinados para homens e mulheres. Questões como a soma das atividades domésticas, sustento material e emocional da família se destacaram entre as respostas das participantes. Traçando uma correlação direta à feminilidade estabelecida, onde "biologicamente", as mulheres estariam mais aptas às atividades domésticas e ao cuidado dos filhos. Com relação à ausência da participação dos homens próximos às participantes na pesquisa, podemos refletir acerca da construção do papel social masculino, onde a expressão de sentimentos, a proposta de diálogo e a produção artística estão vinculadas apenas ao feminino.

As respostas ressaltaram ainda que, a presença de recursos tecnológicos no cotidiano, amplia os significados da linguagem fotográfica, como meio expressivo de ideias e registro de concepções de vida e de mundo. O que colocamos em questão é o fato de que a técnica, como meio instrumental e social, realiza e cria a vida e os espaços. Assim, como a fotografia evidencia o que é próprio de cada sociedade, pudemos discutir e refletir a respeito de estruturas sociais que estão dadas.

Por fim, identificamos entre as respostas que a educação é encarada por todas as participantes como instrumento de mudança. Como afirma Queiroz (2018), a educação preserva em sua gênese a capacidade de construir atores críticos do tecido social. Pessoas capazes de refletir e repensar suas ações na busca por conceber uma sociedade mais equânime, onde a diversidade seja acolhida e não apenas celebrada, de modo a produzir justiça social. Indissociavelmente relacionadas, cultura e educação popular sublinham as ações que evidenciam o protagonismo e o saberes das pessoas que compõem a pesquisa. Isto é, a expressão visual aqui proposta, ao visibilizar o ser mulher e homem camponês, acentuam as urgências do debate e a pertença política fomentadas pelos autores que dialogam com a perspectiva inclusiva da educação. Em um primeiro momento os dados coletados apontam que a fotografia, está presente no cotidiano de todas as participantes e é encarada como modo de expressão de sua visão de mundo. Esta, pode ser usada na problematização das desigualdades de gênero, externando através de imagens, as vivências das participantes.

Considerando o exposto, configuramos como nossa próxima etapa de trabalho, na busca por alcançar o segundo objetivo proposto, a elaboração de espaços de expressão estética, reflexão e diálogo. 
Essa segunda etapa tornará possível a consecução de nossos terceiro e quarto objetivos específicos: analisar os achados obtidos nas dinâmicas propostas; criar exposição virtual fixa em mídia social, a partir das imagens fotográficas desenvolvidas pelas participantes. Após o cumprimento dessas etapas, será possível alcançar nosso objetivo geral, possibilitando o encontro de respostas à questão de partida desse trabalho. No contexto de uma educação emancipatória, que é o cerne da Educação Popular, pode contribuir com a reflexão, debate e proposição de mecanismos eficazes de combate às desigualdades fundamentadas nas diferenças de gênero e nos papéis sociais atribuídos a cada grupo. Por fim, ansiamos que a pesquisa contribua para discussões relevantes no campo, possibilitando elucubrações profícuas acerca dessas questões, tão presentes e significativas no cotidiano moderno.

\section{Agradecimentos}

Agradecemos às componentes do Coletivo de Mulheres do assentamento onde a pesquisa se desenvolveu, à Coordenação de Aperfeiçoamento de Pessoal de Nível Superior CAPES, à Universidade Federal Fluminense - UFF e ao Programa de Pós-graduação em Ciências, Tecnologia e Inclusão - PGCTIn, por possibilitarem a realização dessa pesquisa. Agradecemos ainda, ao Congresso Íbero-americano de Investigação Qualitativa - CIAIQpelo fomento à divulgação científica propiciada na apresentação e publicação desse trabalho.

\section{Referências}

Alentejano, P. R. (2011). O norte fluminense, a luta pela terra e a política de reforma agrária no estado do Rio de Janeiro. In: Pedlowski, M. A.; Oliveira, J. C. P.; Kury, K. A. Descontruindo o latifúndio: a saga da reforma agrária no norte fluminense. Rio de Janeiro: Ed. Apicuri.

Althusser, L. (1985). Aparelhos Ideológicos do Estado: notas sobre os aparelhos ideológicos do estado. ( $2^{\mathrm{a}}$ ed.). Rio de Janeiro: Edições Graal.

Beauvoir, S. (1960a). O segundo sexo: fatos e mitos. São Paulo: Difusão Europeia do Livro.

Beauvoir, S. (1960b). O segundo sexo: a experiência vivida. São Paulo: Difusão Europeia do Livro.

Bourdieu, P. A. (2017). Dominação Masculina: A condição feminina e a violência simbólica. (4ª ed.). Rio de Janeiro: Best Bol.

Brandão, C. R., \& Fagundes, M. C. V. (2016). Cultura popular e educação popular: expressões da proposta freireana para um sistema de educação, 61, 89-106. Curitiba: Educar em Revista.

Dias, B. (2011). O I/mundo da Educação em Cultura Visual. Distrito Federal: Editora da Pósgraduação em Arte da Universidade de Brasília.

Louro, G. L. (1997). Gênero, Sexualidade e Educação: Uma Perspectiva Pós-Estruturalista. Petrópolis: Editora Vozes.

Martins, J. S. (2016). Sociologia da Fotografia e da Imagem. (2 ${ }^{\mathrm{a}}$ ed.). São Paulo: Contexto.

Minayo, M. C. de S. (Org.). (1993). Pesquisa social: teoria, método e criatividade. Rio de Janeiro: Vozes.

Mirzoeff, N. (2016a). O direito a olhar. ETD - Educação Temática Digital, Campinas, SP, 18 (4), 745-768, ISSN 1676-2592. Recuperado de http://periodicos.sbu.unicamp.br/ojs/index.php/etd/articleview/8646472

Mirzoeff, N. (1999b). An introduction to visual culture. London and New York: Routledge.

Queiroz, P. P. de. (2018). Pensando a inclusão no processo de escolarização de alunos com deficiência. In: QUEIROZ, P. P. de (Org.). Ensino, Saúde e Inclusão: Olhares e Reflexões. Rio de Janeiro: Autografia.

Santos, M. (2008). Técnica, espaço e tempo: Globalização e Meio Técnico-científico. São Paulo: Edusp.

Thiollent, M. (1984a). Anotações críticas sobre difusão de tecnologia e ideologia da modernização. In: Cadernos de Difusão de Tecnologia. 1 (1). Brasília: EMBRAPA.

Thiollent, M. (2018b). Construção do conhecimento e metodologia da extensão. Revista Cronos, 3 (2). Recuperado de https://periodicos.ufrn.br/cronos/article/view/15654

Triviños, A. Introdução à Pesquisa em Ciências Sociais: a pesquisa qualitativa em educação. São Paulo: Atlas, 1987. 